allusion to the possibility of this being effected. Since he wrote others have taken up the subject. Thus we find, in Dr. Pereira's "Materia Medica,"* the following statement:"Bonnet snggested that the bladder should be injected with a solution of nitrate of potash, and the calculus subjected to the action of electricity in this liquid, in order that the nitrate may be decomposed into nitric acid and potash ; the former of which, it was suggested, would dissolve the phosphates, while the latter would dissolve the uric acid and urate of ammonia."

The above view has since been taken by Dr. Bence Jones, and will be found in a paper lately published in the "Royal Transactions." For my own part, though it may seem presumptuous to fix the limit beyond which human ingennity is not to step, yet there appears so much which is opposed to the possibility of success when contemplating such proposals, that I have no hope whatever of their adoption leading to the desired result.

As regards the treatment of cystitis following gonorrhœa, I have nothing more to say than that the alkaline plan exceeds all others in efficacy. The combination of hyoscyamus with citrate of potash, in half-drachm or scruple doses, repeated every four hours, will generally produce relief. The dose of hyoscyamus must be moderately small, as it is to be so frequently repeated, but twenty minims of the tincture will not be found too much. If inflammation run high, this plan must be combined with the abstraction of blood by leeches or cupping.

The treatment of cystitis, as produced by partial paralysis, depends much upon surgical aid. The bladder should be emptied by the catheter, and the whole of the urine being thus drawn off, the operation may be in like manner again repeated after a few hours. The viseus, thus freed from the presence of an irritating fluid, often recovers its natural condition; but while this is doing we always improve the condition of the inflamed mucous membranes, by keeping the secreted urine alkaline, and the citrate of potash may be advantageously administered at intervals. Wuch has been said of the benefit derived from strychnia and the various preparations of nux vomica, in assisting the paralysed bladder to recover itself. Inasmuch as strychnia is an excellent tonic, it may sometimes do good in judicious hands; but $I$ am not much inclined to believe in its possessing that power over the bladder of which some have spoken so highly.

With respect to the second class of causes productive of frequent micturition, many of them consist, as I have already shown, in the presence of diseases bearing a very general relation to therapeutics. Thus diabetes insipidus and mellitus, and albuminuria frequently cause the symptom. Of these diseases I need only remark, that the remedies best suited to their relief are those which will most benefit the bladder, by lessening the discharge of urine, on the one hand, and, on the other, decreasing the proportion of albumen contained in it. The other causes described, consisting in the presence of hardened fæces in the rectum, and inertness of skin from exposure to cold, need no remark, the treatment being sufficiently obvious. I would say a few words, however, as to the management of calculus in the kidney, when it is keeping up sympathetic bladder irritation. When we have a patient in this plight, we hope for the passage of the calculus as the most desirable termination of the case, and our treatment should therefore apply to the fulfilment of that end. How is this to be effected? Our object must be more especially to lessen spasm, and to prevent the concretion increasing in size. Alkaline treatment is here most valuable. The citrate and tartrate of potash or soda, exhibited at intervals during the day, are not only theoretically indicated as nentralisers of the urine, the acidity of which must irritate the inflamed renal structure, but the action of these remedies, in producing a supercarbonate of the alkali in the urine, is just what we require in order to dissolve the uric acid or phosphatic earthy deposit, and to prevent its increase. I have now beer in the habit of recommending this treatment for some few years, and, where it has been carefully carried out, have been much gratified with the result. In several cases it has appeared to facilitate the expulsion of the concretion; and in one or two instances, where the nrine has been carefully watched, there has been no return of the disease.

In inveterate uric diathesis, where calculi are constantly forming, this plan of treatment may not always gain credit. The calculi already formed may come down as before, and it may not be easy to impress our patients with the soundness of our views when they observe as many calculi as ever entering their urinary canals. The benefit has, however, been to me * Ihird edition, p. 47 . 496 sufficiently obvious, and I an convinced that it is the only true mode of combating the calculous tendency.

When speaking of calculus in the bladder, I alluded to the chemical effects produced by the alkaline supercarbonates, and I may here relate the manner in which anyone can assure himself, without difficulty, of the power they possess of effecting the solution of earthy phosphates. I need say nothing of their action on uric acid.

If we take recently precipitated earthy phosphate, and wash it, and then pour upon it a solution of bicarbonate of soda, allowing digestion to go on in the cold, with occasional shaking, we find that the bicarbonate will dissolve a very notable quantity of the phosphate. This may be shown by boiling the filtered solution, when the earthy salt will fall as a precipitate.

I have next to notice the treatment of hysterical subjects complaining of frequent micturition. Of the pseudo-cases described, little need be said. They require moral management, and some diversity of opinion may exist as to the best course to pursue. Were I to advise, I should say, when you have satisfied yourself that they are deceiving you, tell them privately that they are doing so, and advise them to get out of the scrape by gradually acknowledging themselves cured by remedies which you propose to administer. In this way they are saved from exposure, and by thus compounding with their mendacity, they may be induced to give up such practices for the future. Of course, when this plan is adopted, it is right some responsible member of the family should be made privy to the scheme and the rationale of its action.

If hysteria be really complicated with irritable bladder, we have the means of doing much good. When describing this state, I alluded to the fact that it was not necessary a large flow of urine should occur, in order to produce the symptom of frequent micturition. It would appear that in some cases the skin refuses to act altogether, and nearly the whole of the water discharged from the system has to find its way through the kidney. This may be owing to the feeble and irregular state of the circulation observed in hysteria, and here the irritability may be removed by tonics and stimulants; and when the skin begins to act, as a result of the restoration of action to the extreme vessels, the symptom ceases.

In other cases less aggravated, it would appear that though the skin maintains the power of excreting water, it loses that amount of energy necessary to render it an emunctory of the more solid constituents of the blood. In this way, the excretion of extractive and other matters is thrown more fully on the kidney, and the wrine is apt to become abnormally acid. Here we have an important indication to fulfil, and it becomes necessary, while we administer tonics, that we shonld render the urine of an unirritating character. The use of the citrate or tartrate of potash or soda will here also do all we require, and they may be advantageously administered in combination with antispasmodics. Of these, assafoetida is perhaps the best. It is a disagreeable remedy, it is true, but great benefit accrues from its administration. The cutaneous surface, as we well know, is rendered active during its ingestion, the perspiration possessing the odour of the drug in a marked degree. The kidney, under this treatment, has less acid to excrete, and the irritability of the mucous surfaces is thus lessened. The best form for this unpalatable drug is in pill, and five grains may be given three times a day with each dose of the saline remedy.

\section{THE CATTLE MURRAIN IN SOME OF ITS ASPEOTS.}

By W. LAUder LINDSAY, M.D., Perth.

RECENT inquiries, made by the public as well as by the medical profession, regarding the true nature or pathology of cattle murrains, and epizootics in general, have elicited abundant evidence of the fact, that we possess really comparatively little reliable information thereanent. Sir Joln Tyrrell stated lately (February 27th) in Parliament, that the conclision arrived at by the Royal Agricultural Society of England some years ago, after a discussion on the cattle murrain, was that nobody knew anything at all about it! It is not my intention, however, here to discuss the subject of the pathology of cattle murrain, however desirable that might otherwise be, in anticipation of the dreaded invasion of that devastating plague. It appears to me that we are scarcely yet in a position to arrire at precise 
and accurate conclusions as to the true nature of the various epizootics which from time to time ravage our flocks and herds. We must have an extensive and accurate series of patient and elaborate investigations, with the aid of the scalpel, microscope, and test-tube, before this can be done. I cannot stop to point out the great importance of a thorough knowledge of the etiology and pathology of epizootic diseases in their bearing on the welfare of our herds, the integrity of our agricultural interests, or on the wholesomeness of our daily food. Nor can I describe what appears to me to be the most efficient mode of conducting investigations in the various departments of the natural history of such diseases. This is the less necessary here, inasmuch as I have entered upon this subject in detail elsewhere.* The object of the following remarks is purely suggestive. My wish is briefiy to indicate some of the lessons which we may learn from a consideration of the question of murrains, and more especially to point out the important relation between epizootic and other affections of the lower animals and human diseases.*

In a paper on the "Influence of Cholera on the Lower Animals," read before the Epidemiological Society of London last year, I endeavoured to show, at some length, the great importance of studying, in a more scientific and philosophical manner than hitherto, the diseases of the lower animals, both with a view to placing the natural history of these diseases on a better footing for the future, and to improve our knowledge of the etiology and pathology of certain human diseases; and I drew up a scheme or plan of investigation which might be followed ont by various classes of observers. From the tenour of the discussion which followed the reading of the paper, it appeared that there prevailer amongst the members of the society great scepticism as to the existence of cholera in animals:"Dr. Snow thought there was no ground for believing that the cholera attacked the lower animals and plants...... His impression was that there was no fatal disease prevalent amongst animals cotemporaneously with cholera epidemies."....." Dr. Greenhow akreed with Dr. Snow in thinking that cholera did not affect the lower animals."....." For instance," said Dr. M'William, "it was asserted that, because horses, donkeys, and goats died in great number in the Cape de Verdes during the prevalence of yellow fever at Boa Vista, there was some connexion between the epizooty and the epidemy. This, however, was not the case; for the mortality amongst the lower animals was very clearly attributable to exhaustion from want of food, consequent upon the drying up of the grass at the end of the dry season; and also, in some degree, to over-feeding in this state of exhaustion, when vegetation sprang up with the return of the rainy season-occurrences usual every year in this arid region."....." Dr. Webster and Dr. Chowne considered that had cholera existed amongst animals, the fact could not have been overlooked by the numerous observers, who had given the subject their attention; but would have been long since clearly established."....." The chairman (Dr. Milroy), said that his own experience had led him to the same conclusion. He had made special inquiries on the subject in Jamaica, and conld not ascertain that the lower animals had been affected by the cholera epidemic, though they had been greatly affected by the epidemic of influenza." + I am also aware that there is a prevalent feeling in the profession adverse to the notion that man and the lower animals are subject to the same diseases, which, moreover, are transmissible between different individuals, species, and genera. These ideas, however, are supported by a considerable array of facts, collected by most credible and unbiassed witnesses. Professor Dick, in this country, and equally eminent veterinarians on the continent, have described cholera epizootics in horses, cattle, fowls, and other domesticated or wild animals. Some of these authors have observed that the disease was transmissible, not only between individuals, but between different species and genera; and the possibility of propagating human cholera anongst the lower animals has, I think, been proved by the experiments of several careful observers, both in Britain and on the continent. Were it established that man and the lower animals are liable to the same or similar diseases-are affected by the same poisonous epi-

* The reader is referred for full details regarding the various subjects mooted in this article to the following papers by the author:- "Natural Influenee of Cholera on Plants and the Lower Animals," (Association Medical Journal, Dee. 15, 185t;) "Vacts for Contagionists relative to the Artificial and Accidental Communicability of Cholera," (Ibid, Sept. 15, 185,;) "On the Communicability of Cholera to the Lower Animals," (Edin. Med. and Surg. Journ., April and Oct., 18ð1, Gazette Hebdom. de Méd. et de Chir., Oct. 13 and Nov. 24, 185;;) "Suggestions for Observations on the Natural Influence of Cholera on the Lower Animals," read before the Epidemiological Society of London,

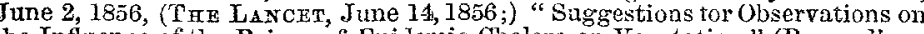
the Influence of the Poison of Epidemic Cholera on Vergetation," (Proceefings of Botanical Society of Fdinburgh for 185̃6, p. 25.)

+ Medical Times and Gazette, June 21st, 1856, p. 631. demic constitution of the atmosphere-there can be no doubt that a study of the diseases of animals would greatly improve our knowledge, and facilitate our study, of human diseases. When doubts exist generally in the profession on the one hand, and trustworthy facts in support of novel views are comparatively few on the other, it becomes our duty, in a matter of such moment, to avail ourselves of the first opportunity of instituting such investigations as will tend to set at rest, not only the general question, but all the minor questions involved therein. The threatened invasion of the cattle typhns of the continent, and the prevalence, in many parts of England at present, of pleuro-pneumonia, or pulmonary murrain, present us apparently with such an opportunity.

It appears to me that the medical profession might contribute materially towards a better knowledge of epizootics, especially in their relation to epidemics, by co-operating with veterinary practitioners, and by directing to the subject the attention of cattle-dealers, farmers, dairym in, grooms, dog-breakers, poulterers, shepherds, and others more or less conversant with the habits and diseases of the lower animals. Amongst points specially demanding, and promising richly to repay, investigation, I would mention the following:-

1. Are the lower animals, and what animals, subject to the same or similar diseases with man? and what are these diseases? Are such diseases in both attributable to the same causes? What are the pathological distinctions or types of disease as modified by habit, \&c.? Are such diseases transmissible between different individuals, species, and genera? and what are the laws of such transmissibility?

2. The influence of the epidemic constitution of the atmosphere on the lower animals; or, in other words, whether, and in what way, are animals affected during epidemics of cholera, \&c., in man-distinguishing the natural from the artificial, or experimental influence?

3. The comparative pathology of the diseases of animals as bearing upon our knowledge of human disease.

I cannot here enter systematically on the discussion of any of these points. I must content myself with giving a few illustrations as texts or nuclei for reflexion or investigation, by way merely of reintroducing the subject to British observers, who may follow it up according to their individual tastes or opportunities. In the papers which I have already quoted (in a foot-note), I have collected from British and foreign journals, so far as I am aware, all the best authenticated instances of cholera epizootics, of the transmissibility of cholera from man to animals, and of the influence of a cholera atmosphere on animal life in different parts of the world. The illustrations which follow consist of citations collected during the last two years, or, in other words, since the publication of the papers in question. They refer for the most part to cholera, to which I have more especially directed my attention; but they have at the same time a more general bearing and a more extensive application. It must be confessed that such instances or illustrations, though in one sense, - in mere number, - comparatively numerous, when the opportunities for observation are considered, are miserably meagre. I have no doubt that they might be vastly multiplied did observers report all that they have seen or known. Shonld the remarks which I have here or elsewhere made stimulate or induce any observer to turn his attention to the subject of the mutual relations of epizootics and epidemics, or to the cognate subjects which I have mooted, my object in bringing them before the profession shall have been fully attained.*

The continental cattle murrain, the "Steppe murrain," the contagions typhus of cattle, possesses several features wherein it more or less closely resembles cholera. I say reserrbles cholera, for there is as yet no ground for supposing that this disease is really cholera. But the resemblance is so striking, that various authors describe cholercic diarrhcea as the fatal mode of termination, or as generally preceding death. We may note also the following features in its natural history. It is essentially a fever; is ushered in by collapse, depression or rigors, this stage being followed by excitement of the system, or, in other words, by reaction; is characterized about the ninth or tenth day by an eruption of pustules in different parts of the body, and frequently at a later stage by difficult respiration; is incurable, intensely contagious, and very fatal, the deaths amounting to from fifty to ninety per cent. By way of comparison, we may recall to mind the collapse, reaction, and typhoid stages of human cholera, the appearance of the cholera exanthem

* The reader who wishes to study, in connexion with this subjeci, that of the opidemic diseases of plants, may consult, in addition to the papers already quoted, Prof. Dauiony, of Oxford, "On the Influence of the Lower Vegetahle Organisms in the Production of Epidemic Diseases."-Edinburgh New Philosophival Journal, July, 1855. 
in the latter stage, and the frequency during the same stage of pulmonary lesions. If we compare the characters of choleroid diseases in animals with the description of the symptoms of human cholera, as given in text-books, we run great risks of error and confusion. We must remember that cholera is a most variable disease, having no one invariable or pathognomonic symptom. Pirogoff, one of the first modern authorities on the pathology of cholera, divides-and very properly, I thinkcholera into simple and complicated; the latter consisting of the following species or types of the disease: 1 . Cholero-dysenteric; 2. Dysentero-choleraic; 3. Cholero-typhoid; 4. Typho-choleraic; 5. Catarrho-choleraic; and 6 . Cholera accompanying the inflammation of various organs. * Dr. Radcliffe, of Bramley, near Leeds, says that a cattle murrain which he saw in Asia Minor in 1855, whilst serving under Omar Pasha, was a "choleraic murrain." +

The "typhus-" or "intestinal-murrain," as we may denominate the Continental or "Steppe murrain," in contradistinction to the more familiar and less deadly "pulmonary murrain" of our own country-the "Lungensuche" of Germany,-appears to be propagable in the same way as cholera-by fomites, such as the clothes of herds, dairymen, and others frequently in contact with diseased animals. I am not aware whether these men themselves are subject to be attacked with a specific or other disease from breathing the poisonous effluvia exhaled by the animals. This, however, is just one of the minor points which it is of great importance to have set at rest, by being satisfactorily cleared up. While the "typhus murrain" is essentially a fever characterised by gastro-enteric complications or symptoms, the "pulmonary murrain" is distinguished by induration and friability of the pulmonary tissue; otherwise it does not appear that it differs from the form which I have just described. It is at present prevalent in England, and has frequently committed great ravages in this country. The study of the "pulmonary murrain," or the pleuro-pneumonia of cattle, is fraught with great interest, as well as practical importance, in connexion with the sale of diseased meat in our markets, - a subject to which the attention of Government has very properly been recently directed by Mr. Gamgee. $\neq$ If animals are subject, according to the highest and undonbted authorities, to pleuro-pnenmonia and typhus, both familiar human diseases, it may be asked, naturally-What is the $a$ priori argument against the idea that they may equally be liable to cholera? I merely start the question, leaving it to be answered or solved by those who assert dogmatically that cholera is essentially a human disease, and that the so-called cases of cholera in the lower animals have been quite different affections!

The " hog distemper" of the United States would appear to be choleroid, or similar to cholera, in some of its symptoms at least. It is much to be deplored, that, from the want of pathological information in such cases, we are reduced to the necessity of speculating on the nature of the disease. The Cincinnati Times states that the symptoms are purging, vomiting, and cramps; that the disease is believed to be contagious and incurable; and that its real nature has not yet been discovered. It has been very fatal in the ohio valley, 60,000 to 70,000 animals having died within a circuit of 100 miles round Cincinnatis in six months.

During the autumn of 1855 , there was great mortality amongst hares about Paris. They did not flee from man, but lay down to die on the walks of parks, \&c., as if exhausted. They were emaciated, the abdomen was distended, and the post-mortem appearances led to the conclusion that typhoid fever was the fatal disense.

Dr. Blenkins, writing, in January, 1856, on the cause of the mortality amongst the fowls in the Crimean camp, says: "Being interested in the discovery of the cause of the great mortality amongst the fowls in camp, $I$ was led to examine several, and invariably found they had died from the same disease that decimated our regiments, and lingers even in this the healthiest period of the year. The entire course in some, and a large portion in others, of the mucous membrane of the alimentary canal, I found displaying more or less intense inflammation, accompanied with thickening, the whole surface being

\section{* Tha Laycet, Oct. 18th, 1856, p. 436}

+ Letter in 'The Times of April 2nd, 1857, on the Cattle Murrain.

\& Letter in The Times of April 3rd, 1857, by Joseph Sampson Gamgee, \&c. Thite Cattle Plague and Diseased Meat in Relation with Public Health and the Interests of Agriculture: a Letter to the Right Hon. Sir George Grey, Bart.,
G.C.B., Secretary of State for the Home Department, by Joseph Sampson Gamgee. London: T. Richards.

§ Daily Express [Edinburgh], Jan. 1st, 1857; and Glasgow Daily News, Feb. 2nd, 1857 .

Archives Générales de Médecine. March, 1856. Report of Proeedings of Academy of Medicine of Paris.

498 covered with an abundant secretion of mucus, intermingled with little pellets of coagulated blood, varying in size from a millet-seed to a pea. In some, the admixture of blood with the mucus was so large, that the secretion precisely resembled red currant jelly. On removing this, the highly vascular papillæ in many places presented a beautiful punctuated appearance. I noticed this vascularity and thickening was most intense in the lower part of the canal. The pathological appearances I have described perfectly correspond with those I have noticed in most of the fatal cases of dysentery amongst the soldiers; and it is interesting to find the disease should occur in the Gallinaceous tribe of birds, which, like ourselves, have not been acclimatized, for they were procured from the transport-ships arriving at Balaclava. The disease appears, as far as I have observed, to be restricted to the new arrivals, for it has not attacked any one of a dozen I procured early in the spring. ...... These have resisted the influence to which the others have succumbed."

In a discussion following a paper read by Dr. Hyde Salter, at the Medical Society of London, "On the Pathology of Hooping-Cough," Dr. Richardson stated that he had seen pigs with croup, small-pox, measles, and plague !

Dr. Furlong, of Antigua, states, on the authority of a letter from the wife of one of the first physicians in Trinidad, that when cholera was epidemic in that island, monkeys, wild and domesticated, died in great numbers from the disease. Travellers found them dead in the woods in every stage of the most malignant cholera. He says, moreover, that they suffered equally from variola when it devastated the island, and that there was the same evidence of contagion amongst the monkeys in the case of cholera as in that of variola. $\neq$ Dr. La Roche, in his work "On Yellow Fever," states that the effects of the epidemic constitution of the atmosphere, during the prevalence of yellow fever in New Orleans and elsewhere, were most striking. "Early in June, 1805, cats began to droop and die; dogs also were severely and fatally affected. Next year cats were again affected, as well as rats...... Many of the cats died numb and torpid, while others were seized with delirium and puking.\$......Even fish and oysters are known at times to participate in the same calamity. In 1798 flies were found dead in great numbers in the unhealthy parts of the city......At Gibraltar, in addition to dogs and monkeys, a goat-herd lost a great part of his flock, and almost the whole ceased to give milk.......At New Orleans, in 1833, there was much sickness amongst horses, cattle, and swine." Again, "in 1819, they died with rotten tongues, and sheep and dogs with their hoofs dropping off, and calves with rotten ears." $\|$ The "braxey" of sheep in Scotland is analogous to the affection last described. During the cholera at Grenoble, not a swallow was to be seen; but these birds re-appeared as the epidemic disappeared. If

M. Lecoq, in September, 1855, made some "experiments on the transmission of rabies from man to the lower animals," at the Veterinary School of Lyons. He inoculated two dogs, one with saliva and the other with bronchial mucus, taken from a man in whom hydrophobia proved fatal at the Hôtel Dieu. He does not feel justified, from the results of a couple of ex. periments, however successful, in giving a decided and final opinion; but he is meanwhile inclined to believe that rabies is transmissible from man to the lower animals.**

Thiersch's experiments on the communicability of cholera to the lower animals are now sufficiently well-known in this country. to He found the cholera evacuations of human patients, at a certain stage of decomposition, very fatal to mice. The symptoms and pathological appearances, as described by him, closely resemble those, if they are not really those, of cholera. It appears to me that veterinary practitioners will experience some difficulty in naming such affections of the lower animals, if they are not to be set down as cholera! Thiersch found that cholera stools, after undergoing decomposition for from six to nine days, caused disease in thirty of thirty-four white mice; twelve of them died, the hair falling off, the ears drooping, the evacuations becoming first white and then watery, the urine losing odour, and becoming suppressed; while the pathological appearances consisted of hyperemia of the small intestines, watery intestinal contents, with epithelial flakes, fatty degeneration of cortical substance of kidneys, and empty bladder.

* Remarks on the Disease affecting the Fowls in the Crimea last Autumn. By Dr. Blenkins, Grenadier Guards. Tre LavakT, Feb. 9th, 1856.

THE LANCET, July 5th, 1856

The Lancet, Dec. 2nd, 1854.

\$ Ia Roche on Yellow Fever, vol. ii., p. 316. Philadelphia, 1855. Also quoted in Brit. and For. Medico-Chirurg. Review, Oct. 1856.

II Ibid, p. 317

đ Gaz. Hebdom. de Méd. et de Chir., Nov. 24th, 1854, p. 1016.

** The Lancer, May 10th, 1856. H† Medical Times, Nov. 25th, 1854, 
In various published papers, already quoted, I have given the experiments of Marshall, of London; Namias, of Venice; Meyer, Bossani, Freschi, Novati, Calderini, Bergamo, Semmola, and others. My own experiments, which are probably amongst the most recent, do not seem to have carried conviction alike to all minds. Thus, while Professor Alison, of Edinburgh, writes, - "That the cholera can be commu nicated to animals by inoculation with this matter of the peculiar rice-water stools has been sufficiently proved by the experiments of Dr. Lindsay in this country,"* Professor Parkes, of London, remarks, "We would mention also here the experiments of Dr. Lauder Lindsay, who appears to have given dogs cholera by making them breathe a choleraic atmosphere, but who, like others before him, could not cause cholera by feeding the dogs on cholera dejections." + A reviewer in the Dublin Quarterly Medical Journal says, "The experiments instituted by Dr. Lindsay, and detailed in a pamphlet reprinted from our esteemed cotemporary, the Edinburgh Medical and Surgical Journal, funnish results somewhat different...... These experiments lead to the inference that cholera was simultaneously developed in four animals, and proved fatal in two of them...... Though Dr. Lindsay's experiments seem to argue more directly [than Meyer's or Marshall's] in favour of the communicability of the disease, we cannot divest our minds of the supposition that had equally miserable animals been subjected to a similar ordeal, from which cholera infection might be presumed as being excluded, closely analogous results would equally have ensued." + A reviewer in the British and Foreign Aredico-Ohirurgical Review, $\$$ says, "Since these reports were completed, an important paper has been partly published by Dr. Lauder Lindsay. ...... It would seem probable that this gentleman has solved the question of the contagion of cholera, by communicating the disease to animals." And lastly, the editor of the Gazette Hebdomadaire, II in an introductory note to a paper by me on the "Transmission du Cholera aux Animaux, nouveaux détails," remarks- "En gardant la même réserve que l'auteur sur les résultats de ses expériences (voir Gazette Hebdomadaire, No. 54, Oct. 13, 1854), nous nous faisons un devoir de déclarer que nous attachons comme lui, une très haute importance aux problèmes soulevés dans la note qu'il veut bien nous addresser. C'est par des récherches de ce genre qu'on pourrait espérer d'acquérir quelques notions vraiment neuves et elévées sur l'étiologie et la pathologie du cho. léra." In reply to those who doubt or deny that the disease in the animals on which I experimented was cholera, I can only state that I showed the pathological appearances and described the symptoms to the late Professor Barlow, of the Edinburgh Veterinary College, who agreed with me that we were shut up to the conclusion that the animals in question had suffered from cholera as it occurs in man. While doubts and adverse theories or opinions do not disprove the fact advanced by me-that the symptoms and pathological appearances in these animals were quite those of cholera and of no other disease with which veterinary practitioners are acquainted, and that the disease was artificially induced by methey argue strongly in favour of further experimentation, the result of which may be either to prove or disprove, corroborate or set aside, the results at which $I$, as well as other experimenters, have arrived.

M. Bourguignon, in a paper read before the Medical Society of Paris, states that the acari of the lion are similar in habit, \&c., to those which infest man; and that scabies can be communicated from the lion to man. If In the report of one of the meetings of the Academy of Medicine of Paris last year, it is stated that in the horse a new species of acarus has been discovered, which is capable of communicating scabies to man. *** It would appear that the horse is liable to be infested with two itch insects, or species of acari: the one sufficiently wellknown, occurring also, as it does, in many herbivorous animals; the other, not hitherto recognised as a parasite of the horse, and identical in habit, \&c., with that of carnivorous animals. R. J. Richardson, inspector of nuisances to the Board of Health at Newton Heath, near Manchester, in his examination before the "Aclulteration of Food Committee," stated that many animals sold by butchers die from "Tick disease," which

* "Application of Statisties to Questions in Medical Science," (Edinburgh Medical Journal, Nov. 185̃.)

+ Review of Snow on the Communication of Cholera, (Brit. and For. MedicoChirurg. Review, April, 1855, p. 463.)

$\ddagger$ Feb. 1855, p. 162, Review of works on Cholera.

July, 1854, Review of works on Cholera.

Nov. 24, 1854, p. 1044 .

The Lancet, May 12th, 1855

** Archives Génér. de Méd., March, 1856. was supposed to be contagious, and would extend to the human frame."*

In conclusion, I would only further remark, that one great reason why many of the instances hitherto recorded of cholera in the lower animals, - of diseases transmissible between man and animals, -and of epizootic or other diseases occurring in animals coincidently with epidemics in man,- -have not been regarded as of much value or reliable, is the deficiency of pathological information regarding them-the want of post mortem investigation. This is a point which it is of the utmost importance to keep in view in all future investigations and experiments. $†$

Perth, April, 1857.

\section{HISTORY AND PRACTICE OF URETHRO- PLASTY.}

BY HENPY THOMPSON, M.B., F.R.C.S.,

HONORARY SURGEON TO THE MARYLEBONE INYIRMARY, ASSTSTANTSURGEON TO UNIVERSTYY COLLEGE HOSPITAL.

No. IV.

Respecting the propriety of first making an opening into the urethra from the perinæum, in order to divert the stream of urine from an antescrotal fistula, which it is proposed to close by a plastic operation, Dieffenbach wrote as follows, after the experiment had been tried and found successful :-

"There is still an important remedy, in order to secure the success of the larger urethro-plastic operations, by avoiding the effusion of urine, and so promote the union of the borders of the wound by sutures: this is, the making an opening into the canal at its posterior part, and the leading away the urine from thence by an elastic catheter introduced into the bladder. I naturally arrived at this idea from the well known observation, that when two openings exist in the canal, - one anterior, the other posterior, - the former heals withont difficulty after cauterization, provided the posterior be large, and permits the urine to flow through it. Still more certain is this to happen when we introduce a catheter through the posterior opening into the bladder...... It is very probable that Ségalas is indebted to the coexistence of perineal with antescrotal fistulæ, for the reparation of important defects of the latter kind, so that he could prevent, by the use of the catheter through the posterior opening, the contact of urine with the place of operation. The incision into the canal for the leading away of the urine from the place of operation, is never indicated with small fistulæ; as we should then be curing a small evil by means of a greater one. We should only apply this operation to cases with considerable loss of substance, in which case the balance of advantage will be on onr side, as having closed the great (anterior) opening, we shall have only the smaller (posterior) opposed to us."

He then goes on to describe the ordinary method of making the boutonnière, or median incision into the urethra from the perinæum upon a grooved staff, and introducing a catheter into the bladder through it; and adds, " Every two or three hours the urine is to be drawn off through the catheter. Only when the anterior opening has been soundly cicatrized after the autoplastic operation, are we to introduce a fresh catheter, and occupy ourselves with the cure of the perineal opening, which generally follows without difficulty when we permit that catheter to remain throughont the whole track of the urethra, and frequently cauterize the perineal opening." +

But Dieffenbach was not the first to open the urethra behind a fistula for the purpose of facilitating the performance of urethroplasty; nor indeed until late years does he appear to have considered it a measure to be advised, although he may have been the first to suggest the possibility of its offering a means of success in obstinate cases; and he qualifies the advice at that time by adding that " he has renounced the method," $\$$ that is, on theory, on the ground that although the anterior fistula might heal through the agency of the newly-made open-

* The Times, March 13th, 1856.

+ The reader will find a summary of the more important epizootics in Virchow's " Handbuch der Speciellen Pathologie und Therapie." Band II, 1st Abtheilüng. See also Census of Ireland for 1851, vol. v., pp. 358-9, (Analysis of Epizooties from 1837.)

$\$$ Dieffenbach, Op. cit. pp. $536-7$

§ "Sur quelques nouvelles méthodes pour obtenir la guérison des ouvertures, \&c." A paper in the Gazette Médicale de Paris, 1836. By J. F. Dieffenbach. The suggestion appears also in the author's early work, "Chirurgische Erfahrungen." Berlin, 1829. 